FORMA NOVELESCA, VIOLENCIA Y MERCADO: UNA NOVELA HISTÓRICA CHILENA DEL SIGLO XXI

\author{
Fictional Form, Violence and Market: a Chilean Historical Novel from \\ the 2lst Century
}

\author{
Carlos Alexis Hernández Tello \\ UNIVERSIDAD DE CHILE (Chile) \\ clhernan@uc.cl
}

Resumen: el desarrollo de la novela histórica chilena del siglo XXI es un fenómeno que no puede desligarse de las transformaciones económicas experimentadas por el país durante las últimas cuatro décadas, así como tampoco de los hechos de violencia y terror que fueron necesarios durante el proceso dictatorial para la implementación forzada de la nueva ortodoxia neoliberal. En ese sentido, el artículo pretende desplegar una reflexión sobre las formas que ha ido adquiriendo la novela histórica nacional en el marco de dicho modelo económico, y en el que la disolución del binarismo ficciónrealidad constituye el principal rasgo de las formas novelescas que inauguran la producción de novelas históricas chilenas del siglo en curso.

Palabras clave: forma novelesca, novela histórica chilena, violencia, neoliberalismo, ficción/realidad Abstract: the development of the Chilean historical novel from twenty-first
century is a phenomenon that cannot be disengaged both from the
economic changes experienced by the country during the last four decades
and from violent acts and terror that were necessary in the dictatorship
process for the forced implementation of the new neoliberal orthodoxy. In
the same way, the article pretends to illustrate a reflection concerning the
forms that historical novel has been acquiring in this economic framework,
in which the dissolution of the fiction-reality binarism constitutes the main
aspect of fictional forms that inaugurate the production of Chilean
historical novels in this century.
Keywords: Fictional Form, Chilean Historical Novel, Violence, Neoliberalism,
Fiction/Reality 


\section{Panorama histórico-teórico de la novela histórica chilena actual}

Una breve revisión a los acontecimientos de los últimos cuarenta y cuatro años en Chile revela, sin ambages, el trastorno revolucionario del que ha sido víctima la sociedad chilena. Si atendemos a lo que establece Hannah Arendt en Sobre la revolución (1963), observamos que " $[\mathrm{A}]$ penas puede negarse que una de las razones por las cuales las guerras se han convertido tan fácilmente en revoluciones y las revoluciones han mostrado esta nefasta inclinación a desencadenar guerras es que la violencia es una especie de común denominador de ambas" (Arendt, 2013: 25). En efecto, el golpe de Estado del 11 de septiembre de 1973, que sepultó el proceso revolucionario de un "socialismo democrático" para reemplazarlo por un neoliberalismo radical que redirecciona el rol del Estado, convirtiendo a este último en garante de un paquete de medidas económicas en que el mercado opera ad libitum, no es otra cosa que la violencia como marco inevitable para la inserción de las medidas revolucionarias postgolpe. En ese sentido, nada es más pertinente que la conclusión de Arendt de que "toda organización política que hayan podido construir los hombres tiene su origen en el crimen" (28). Crimen y neoliberalismo, o bien, violencia y mercado, son categorías esenciales para aprehender las transformaciones histórico-económicoculturales de Chile en el último medio siglo. Si asumimos, como lo hiciera Lucien Goldman en 1964 en Para una sociología de la novela, que la forma de la novela es una manifestación susceptible de metamorfosis en perspectiva de las transformaciones económicas,' no es extraño que la novela histórica chilena del siglo en curso haya adoptado mecanismos representacionales para asumir el pasado reciente.

De ahí que en adelante sostendremos que la novela histórica chilena actual ha imbricado, en su forma discursiva, las matrices histórico-económicas que dieron un curso nuevo al devenir de la sociedad chilena. No obstante, cuando nos referimos al viraje que ha experimentado la novela chilena de este siglo no lo hacemos con una pretensión totalizadora. Es por ello que preferiremos hablar, para nuestros fines de investigación, de una novela histórica chilena del siglo XXI, en el sentido que le asignamos a la preocupación que ha tenido la novela chilena de temática histórica en cuanto al relato de los luctuosos hechos postgolpe de Estado y su trascendencia en el devenir nacional, así como también a las formas empleadas y los mecanismos representacionales que llaman a descreer de la distinción ficción-realidad que han perpetuado la subalternidad de los estudios literarios a las investigaciones historiográficas. De este modo, si bien le endosamos

\footnotetext{
${ }^{1}$ Específicamente, Goldman afirma: “...la forma novelesca es [...] la transposición al plano literario de la vida cotidiana en la sociedad individualista nacida de la producción para el mercado. Existe una homología rigurosa entre la forma literaria de la novela [...] y la relación cotidiana de los hombres con los bienes en general y, por extensión, de los hombres entre sí, en una sociedad que produce para el mercado. La relación natural, sana, de los hombres y de los bienes es, en efecto, aquella en que la producción se halla regulada conscientemente por el consumo futuro, por las cualidades concretas de los objetos, por su valor de uso. Ahora bien, lo que caracteriza la producción para el mercado es, por el contrario, la eliminación de esta relación de la conciencia de los hombres, su reducción a lo implícito gracias a la mediación de la nueva realidad económica creada por esta forma de producción: el valor de cambio" (Goldman, 1975: 24; cursivas del original). La ortodoxia neoliberal, impuesta en Chile por medio de fusiles y centros de tortura y exterminio, revela la maroma que experimentó el Estado Benefactor: la producción concebida en la elaboración de valores de uso fue reemplazada sin más por la producción a ultranza de valores de cambio, transformando el ethos nacional y redireccionando, subrepticiamente, sus prioridades materiales y existenciales. De ello precisamente darán cuenta las novelas históricas chilenas del siglo XXI.
} 
un rol cultural importante a la atención que han concitado otros episodios de la historia nacional en el campo de la novela y sus formas de expresión, no nos parece arriesgado sostener que la preocupación epistemológica que ha esgrimido la novela histórica chilena actual por entender el pasado reciente se ha ido imponiendo paulatinamente como instancia cultural hegemónica.

La categoría "novela histórica" ha resultado, a nuestro entender, problemática por cuanto ha operado con dos sistemas aparentemente distintos de aproximación a la realidad o de organización de la experiencia. La distinción ficción-realidad ha sido inherente a los esfuerzos de autores como Georg Lukács por construir un esquema de ingreso a los textos narrativos que se han arrogado la decodificación del pasado, de antaño u hogaño. En las exégesis de este teórico el lector observa dos aspectos: Primero, y como acabamos de señalar, la articulación de un estudio que no puede prescindir del binarismo ficción-realidad para referirse a la novela y a la Historia, respectivamente. Segundo, la convicción de que el relato se centra en las existencias de aquellos sujetos que no dirigen los procesos de transformación histórica, sino más bien son el receptáculo de los mismos y participan de ellos de manera marginal; mientras que por otra, la Historia daría cuenta de los episodios trascendentes, y en cuyo relato participan los actores reales que fungen de directores de los procesos. En este sentido, las afirmaciones de Lukács son claras:

Poco importa, pues, en la novela histórica la relación de los grandes acontecimientos históricos; se trata de resucitar poéticamente a los seres humanos que figuraron en esos acontecimientos. Lo importante es procurar la vivencia de los móviles sociales e individuales por los que los hombres pensaron, sintieron y actuaron precisamente del modo en que ocurrió en la realidad histórica. Y si bien a primera vista pueda parecer paradójico, después de un examen más detenido es evidente que una de las leyes de la plasmación poética consiste en que para hacer patentes tales móviles humanos y sociales de la actuación, son más apropiados los sucesos aparentemente insignificantes que los grandes dramas monumentales de la historia universal [...]. Así pues, de lo que se trata en la novela histórica es de demostrar con medios poéticos la existencia, el "ser así" de las circunstancias históricas y sus personajes. (Lukács, 1966: 35-37; cursivas del original)

En el ámbito latinoamericano, Seymour Menton (1993) ha orientado el estudio de la novela histórica hacia otras preocupaciones, en lo que ha denominado Nueva Novela Histórica. Menton anota que durante los años transcurridos desde 1979 hasta 1992 ha habido un gran auge de producciones narrativas que abordan el problema de la historia literariamente, pero ya no como lo hizo la novela histórica decimonónica, es decir, relatar los hechos desde los ciudadanos comunes, la gleba sin historia, sino tomando como referente las grandes figuras de la humanidad para plantear reescrituras de su labor como sujetos históricos (Menton, 1993: 43). Así, Menton agrega una lista de características de la Nueva Novela Histórica como un concepto alterno al de la novela histórica europea del siglo XIX: ficcionalización de personajes que vivieron en el pasado, metaficción o comentarios del narrador sobre el proceso de creación, intertextualidad, pero sobre todo, el hecho o personaje histórico abordado por la novela debe estar situado en un pasado lejano no vivido por el autor. Ante este auge de producciones novelescas que toman como referente la historia para ser enunciadas, Menton señala como alguna de las posibles razones: "A mi juicio, el factor más importante en estimular la creación y la publicación de tantas novelas históricas en los tres últimos lustros ha sido la aproximación del quinto centenario del descubrimiento de América" (43). Como se desprende de la propuesta de Menton, las categorías de Literatura e Historia (ficción-realidad) siguen operando dicotómicamente. 
Ahora bien, en el espacio chileno las voces críticas que han focalizado su atención en el estudio de la novela histórica se desmarcan en diferentes grados de esa concepción binarista de entender el género, lo cual responde en nuestra lectura a las formas que ha ido adoptando la novela como consecuencia de los crímenes de la dictadura y la postrer instalación del modelo económico neoliberal, es decir, las transformaciones económicas en una sociedad para el mercado, según las aclaraciones de Goldman. Un estudio importante en esta línea es el de Fernando Moreno, para quien la novela histórica chilena postgolpe constituirá el bastión revisionista de una historiografía problemática, a la vez que propondrá una tríada de clasificación del corpus en perspectiva de dicha concepción revisionista:

Apropiándose de la Historia silenciada, impugnando la historia oficial, inventando la historia, los textos contemporáneos optan por la senda de una narratividad cuestionadora que se sitúa por encima del conformismo de las verdades absolutas. De modo que la tematización de la Historia ya no se concreta tan sólo a partir de una simple opción de verosimilitud y de estricta o fiel representación de un determinado segmento de la realidad. Junto con este intento de exponer aquello que ha sido deformado o silenciado por la historia, en algunos casos la novela actual propone esta ficcionalización insistiendo en el reconocimiento de que la veracidad de la materia discursiva es una función de su propia actividad lingüística y compositiva, desde la certeza de que la literatura es actividad constituyente de significado y no mera actividad que significa, que la literatura es texto contingente y alusivo, invocador y configurador de la interdiscursividad dentro de la cual se inserta como opción y recurso posible y no como palabra sagrada o discurso inmutable [...]. Por una parte, los textos se vuelcan hacia el pasado inmediato, hacia la dictadura, "su escuela" y sus secuelas [textos catárticos]; ${ }^{2}$ por otra, hacia un pasado más o menos lejano, hacia períodos fundacionales o significativos de la historia chilena [novela arqueológica]. Finalmente, hay textos que engarzan presente y pretérito, restableciendo vínculos y desplegando significaciones que señalan y establecen las posibles lecciones de la historia y advierten sobre la necesidad de recurrir al recorrido para hacer o rehacer el camino [novela transitiva]. (Moreno, 2001: 272-273)

Resulta interesante el atisbo de Moreno pues de él se desprende que asume la ficcionalización del pasado no como un atributo intrínseco al acto narrativo literario, sino más bien como el atributo de cualquier dispositivo narrativo por cuanto constituyen "actividades lingüísticas", y como tales, susceptibles de ser significadas y reconstruidas en función de intereses culturales e ideológicos. En ese sentido, la forma de la novela histórica chilena del siglo XXI que propondremos se inserta en un espacio teórico en que se torna cada vez más compleja e inaceptable una exégesis que ingrese a las novelas como ficciones tributarias de la verdad histórica, asumiendo una subalternidad disciplinaria y epistémica no acorde con los procesos representacionales análogos que exhiben Literatura e Historia en el contexto neoliberal imperante. En perspectiva de esta línea teórica, nos parecen también certeras las reflexiones de Antonia Viu en Imaginar el pasado, decir el presente. La novela histórica chilena (1985-2003) (2007), pues además de la

\footnotetext{
${ }^{2}$ Esta modalidad de textos catárticos es la forma dominante en la novela histórica chilena que estudiaremos brevemente en el siguiente apartado. Como puede constatarse, dista plenamente de la preceptiva de Menton, por cuanto en la Nueva Novela Histórica los hechos referidos debían perentoriamente no haber sido vividos por su autor. En el caso de nuestro corpus de trabajo, la mayoría de los hechos referidos han sido parte de la experiencia personal de sus autores, lo cual podría concebirse también como un aliciente que contribuye a la disolución del binarismo ficciónrealidad que intentamos demostrar.
} 
propuesta de clasificación de su corpus de trabajo (insignia, memorial, inscripción, retablo, semblanza y viñeta), resitúa el estatuto epistémico de Literatura e Historia concibiéndolas como representaciones en las que subyacen mecanismos discursivo-ideológicos indistintos: "...la novela histórica está fundada en la historiografía. $Y$ en este punto aparece el que a mi juicio es el concepto metodológico central [...], el de representación. Tanto la historiografía como la novela histórica son eso, representaciones" (Viu, 2007: 13). Sin embargo, es en el desglose de elementos que constituyen el artificio representacional, tanto para el novelista como para el historiador, donde reside la propuesta metodológica basal de esta autora, pues "representación" será seleccionar fragmentos de la realidad, darles coherencia llenando vacíos por medio de la imaginación y el uso intencionado del lenguaje, así como también el componente ideológico: "La imagen configurada por el historiador [y también por el novelista] al seleccionar, imaginar y narrar los hechos del pasado produce un saber referencial respecto de dicho pasado, pero también queda revestida de un poder ideológico que modifica la realidad y la hace apropiable para diversos fines" (53). En este sentido, tanto novelista como historiador operarían con los mismos insumos metodológicos para ingresar al pasado. El uso de fuentes, del que también repara Viu en sus reflexiones, ${ }^{3}$ no sería en una concepción como la que proponemos patrimonio administrado por el historiador, sino un material disponible para dar pábulo a la maquinaria narrativa de quien se disponga a la labor de referir los hechos del pasado.

\section{Las formas de una novela histórica chilena del siglo XXI: apuntes para una relectura}

El presente apartado despliega brevemente las formas en que la novela histórica chilena del siglo XXI se ha manifestado. Culmina esta sección con el escueto examen de dos novelas, Septiembre sin primavera (2013) de Fernando Moure y La gran ciudad (Una novelita finisecular de agitación y propaganda) (2014) de Omar Saavedra Santis, que vendrían a ejemplificar nuestra propuesta basal, vale decir, la convicción de que el artificio novelesco será el mecanismo primario para engarzar violencia dictatorial y la instalación del neoliberalismo como resultado de dicha violencia, a la vez que tal forma oblitera el binarismo ficción-realidad que hemos caracterizado como sintomático de la novela histórica europea y latinoamericana, al menos hasta los albores de las políticas de shock económico difundidas por Milton Friedman y Arnold Harberger, asumidas primeramente en Chile, para luego ser inoculadas en la órbita mundial bajo los mandatos de Ronald Reagan y Margaret Thatcher.

Resulta revelador el examen de la categoría "autor como productor" elaborada por Walter Benjamin en su ya clásico trabajo de 1934. En él, el estudioso alemán concebía la labor del creador como sujeto cuyo trabajo artístico debía, perentoriamente, transformar los medios de producción existentes. Así lo enuncia a propósito de la obra de Bertold Brecht:

...el lugar del intelectual en la lucha de clases sólo pude ser establecido -o mejor: elegido - con base en su posición dentro del proceso de producción. Para referirse a la transformación de las formas de producción y de los instrumentos de producción en el sentido de una intelectualidad progresista

\footnotetext{
3 "En un primer momento el historiador representaría al elegir las fuentes y documentos con los que trabajará por los datos que aportan y por la garantía de veracidad que le ofrecen. Esto significa que el pasado no ingresará al texto historiográfico tal y como ocurrió, sino recortado, encuadrado como una foto en la que junto con la opción de seleccionar un fragmento de la realidad, se elige excluir todo lo que no formará parte de la composición. Ambas opciones, incluir y excluir, serán significativas en la imagen del pasado que surja [...]" (50).
} 
—interesada por tanto en la liberación de los medios de producción; útil por tanto en la lucha de clases- Brecht ha elaborado el concepto de refuncionalización. Él fue el primero en plantear a los intelectuales esta exigencia de gran alcance: no abastecer al aparato de producción sin transformarlo al mismo tiempo, en la medida de lo posible, en el sentido del socialismo. (Benjamin, 1934: 10; negrita en el original)

$\mathrm{Al}$ estudiar las formas de la novela histórica chilena actual observamos que varios de los autores en cuestión pergeñan maquinarias narrativas, engranajes novelescos, orientados a formar parte insoslayable del proceso de producción neoliberal, pero al mismo tiempo se nutren de sus estrategias de mercado para ingresar al medio social $y$, de este modo, iniciar una contraofensiva cuyo rol desestabilizador se enmarca en el alcance que tiene la crítica que despliegan. $\mathrm{Si}$ bien es cierto, y como lo anotaría certeramente Fredric Jameson en 1984, son cuestionables las posibilidades de un arte crítico y político en la era del capitalismo tardío, ${ }^{4}$ lo cierto es que un cúmulo de autores nacionales viene sosteniendo una lucha cuyo objetivo apunta precisamente a arremeter contra las dinámicas neoliberales que constriñen a la ciudadanía. Pues, de acuerdo a las aclaraciones de economistas como Manfred Steger y Ravi Roy, o historiadores como Gabriel Salazar y Julio Pinto, ${ }^{5}$ el paquete de medidas económicas neoliberales no dejan de ser objeto del plot novelesco, de las problemáticas suscitadas a los personajes de los mundos narrativos en cuestión. Todo ello, demás está señalarlo, se sitúa en un proscenio histórico en el que el terror es práctica consuetudinaria del accionar castrense.

Ya trazado el mapa histórico-teórico, sostendremos a partir de ahora que seis serán las formas novelescas que se constituyen como dominantes en la novela histórica chilena del siglo XXI, las que, en uno u otro sentido, construyen maquinarias representacionales destinadas a disolver el binarismo ficción-realidad. Éstas pueden sintetizarse como siguen (1) "Voces testimoniales de la resistencia", eje de análisis en el que las novelas a examinar recurren al procedimiento discursivo de la pluralidad coral como artefacto que da cuenta de sujetos múltiples inmersos en un torbellino de violencia y terror. (2) "Lecturas de la postdictadura", modalidad que comprende obras que ofrecen relatos de reinterpretación o revisionismo de la transición, estableciendo una continuidad en el presente postdictatorial de las estructuras institucionales y económicas implantadas en dictadura mediante la tortura y la muerte. El ejercicio de estas novelas se sitúa en diagnosticar el grado en el que la economía de mercado ha suplantado los proyectos colectivos de antaño, respaldados por un Estado de Bienestar pero que en el presente de los relatos, dicho Estado se ha metamorfoseado en garante del nuevo orden económico; (3) "Alegorías de la

\footnotetext{
${ }^{4}$ La reflexión de Jameson se instala, como es sabido, en el ámbito de una concepción posmoderna, entendida ésta como dominante cultural, y que vislumbra la producción artística cuya razón de ser no puede desdoblarse de su carácter de mercancía, la cual es resultado inmanente de las dinámicas del mercado. En este contexto creemos debe ser entendida la pregunta capital sobre "cuáles son las posibilidades de un arte crítico o político en el período posmoderno del capitalismo tardío", que se planteará el autor estadounidense (Jameson, 1991: 26).

${ }^{5}$ Las medidas económicas a las que se refieren Steger y Roy se reducen a la fórmula que denominan D-L-P, esto es, desregulación de la economía, liberalización del comercio y de la industria, y privatización de las empresas estatales. Como corolario, Salazar y Pinto anotan sucintamente lo que tales medidas han significado en la escena social nacional: "Dependencia, vulnerabilidad, inequidad y pobreza: a final de cuentas, y pese a la vistosidad de los signos de nuestra modernización, el cuadro que presenta este fin de siglo [el XX] no se ve tan diferente, al menos en sus aspectos estructurales, del que exhibía hace un siglo atrás la vilipendiada 'república salitrera' [predominancia, incluso hoy en el siglo XXI, de una economía primario-exportadora]" (Salazar y Pinto, 2014: 60 Tomo III). Insistimos en que estos elementos son transversales al acontecer novelesco del corpus, y que como tales incidirán en las formas que adopten las novelas al momento de irrumpir en la escena cultural chilena.
} 
dictadura", es decir, las que, a diferencia de los relatos que se empezaron a publicar desde finales de los años setenta hasta mediados de los ochenta, no serían necesariamente "alegorías de la derrota" (según la expresión acuñada por ldelber Avelar, 2000), sino más bien artificios narrativos alegóricos de resistencia, de resistencia al olvido y de resistencia al mercado. Lo que puede rastrearse es que estas novelas, al mismo tiempo que están representando la desarticulación de un pueblo por medio de la tortura y las balas, paralelamente revelan un diagnóstico que establece las bases para un contraataque político. En ese sentido, estas novelas no serían relatos abúlicos que dan cuenta de una derrota sin más, sino que a la vez irrumpen en la escena cultural postdictatorial como dispositivos performativos de acción política con un alto potencial histórico-cultural; (4) "Ucronías de la dictadura y la postdictadura", eje en el que se enmarcan novelas que, acordes a las dinámicas de dicha modalidad, proyectan o imaginan un futuro alternativo al ya conocido, o bien, como lo elaboraran obras de la envergadura de Huxley u Orwell, formulan hipótesis narrativas sobre las consecuencias que implicaría en la sociedad chilena la perpetuación de una economía de mercado totalmente desregulada y privatizada; (5) El "relato detectivesco" es otra de las categorías en que las novelas de la postdictadura interpelan la violencia dictatorial y su postrer modelo económico neoliberal. El "neopolicial criollo", como lo ha llamado José Promis (2005), nos presenta a un detective degradado en un mundo degradado en busca de valores auténticos (según el esquema de Lukács en su Teoría de la novela). Ese sujeto degradado es el resultado de la violencia dictatorial, de la que es víctima incluso durante la época de democracia, tiempo en que se manifiesta tenazmente el largo brazo de los militares y su dispositivo económico; (6) La última forma novelesca, "narrativas contraculturales", aglutina obras que sostienen una pugna contra la cultura hegemónica mercantilizada de la actualidad, subsumida en el pantano del dinero, y proponiendo una alternativa que concibe la creación literaria como artefacto primario para desarticular el discurso basal del neoliberalismo. De este modo, en estos relatos subyace una concepción ilustrada de la práctica escritural, la cual es trasvasada al asunto de los relatos, pero también al artificio poético. ${ }^{6}$

\section{Septiembre sin primavera de Fernando More: voces, pasado y testigos}

Para ingresar a la forma novelesca "voces testimoniales de la resistencia" resultan necesarias algunas precisiones teóricas. La primera, por cuanto despeja ciertos aspectos referentes a la pluralidad de voces que conforman los relatos testimoniales, esto es, el carácter subjetivo que comporta la articulación de una

\footnotetext{
6 El lector interesado puede consultar las siguientes novelas que constituirán ejemplos representativos de las formas novelescas que estamos proponiendo para entender el fenómeno de la novela histórica chilena del siglo en curso. Para la primera modalidad, "voces testimoniales de la resistencia", las novelas a considerar son Tengo miedo torero (2001) de Pedro Lemebel, Milico (2007) de José Miguel Varas y Hacia el final de la partida (2007) de Guillermo Rodríguez y la ya citada novela de Fernando Moure. Para el eje "lecturas de la postdictadura", dos obras significativas son Estrella distante (1996) de Roberto Bolaño y El último. Sumarísima relación de la historia de Samuel Huerta Mardones (2004) de Omar Saavedra Santis. Para la forma "alegorías de la dictadura", una novela a considerar es La ley del gallinero (1999) de Jorge Guzmán. Para la modalidad "ucronías de la dictadura y la postdictadura", dos novelas representativas son 2010 , Chile en llamas (1998) de Darío Osses y Synco (2008) de Jorge Baradit. Para el eje "relato detectivesco", buenos ejemplos son las novelas Hot line (2002) de Luis Sepúlveda, La oscura memoria de las armas (2008) y La música de la soledad (2014) de Ramón Díaz Eterovic, Las manos al fuego (2006) de josé Gai y La otra mujer (2010) de Roberto Ampuero. Por último, para la modalidad "narrativas contraculturales", un grupo de obras importantes son Historia de una absolución familiar de Germán Marín, trilogía integrada por Círculo vicioso (1994), Las cien águilas (1997) y La ola muerta (2005); Fuenzalida (2012) de Nona Fernández; Lacra (2013) de Marcelo Leonart y la ya anunciada novela de Saavedra Santis.
} 
narración que transmite una experiencia propia o ajena. Se vincula a lo anterior el problema epistemológico asociado al grado de verdad otorgado a relatos de esta naturaleza, pues en su complexión subjetiva estas voces "no estarían a la altura" de un aparato discursivo historiográfico que diseñaría su andamiaje en base a un archivo que dotaría de empirismo a su relato. Para estos fines, son esenciales las precisiones que realiza Beatriz Sarlo en Tiempo pasado. Cultura de la memoria y giro subjetivo. Una discusión (2005). Afirma la estudiosa argentina:

La idea de entender el pasado desde su lógica (una utopía que ha movido a la historia) se enreda con la certeza de que ello, en primer lugar, es completamente posible, lo cual aplana la complejidad de lo que se quiere reconstruir; $y$, en segundo lugar, de que se lo alcanza colocándose en la perspectiva de un sujeto y reconociendo a la subjetividad un lugar, presentado con recursos que en muchos casos provienen de lo que, desde mediados del siglo XIX, la literatura experimentó como primera persona del relato y discurso indirecto libre: modos de subjetivación de lo narrado. Tomadas estas innovaciones en conjunto, la actual tendencia académica y del mercado de bienes simbólicos que se propone reconstruir la textura de la vida y la verdad albergadas en la rememoración de la experiencia, la revaloración de la primera persona como punto de vista, la reivindicación de una dimensión subjetiva, que hoy se expande sobre los estudios del pasado y los estudios culturales del presente, no resultan sorprendentes. Son pasos de un programa que se hace explícito, porque hay condiciones ideológicas que lo sostienen. Contemporáneo a lo que se llamó en los años setenta y ochenta el "giro lingüístico", o acompañándolo muchas veces como su sombra, se ha impuesto el giro subjetivo. (Sarlo, 2005: 21-22; cursivas del original)

$\mathrm{Si}$, como puede observarse en la reflexión de Sarlo, la subjetividad en los relatos de memoria ha venido reclamando en las últimas décadas un estatuto epistémico que ha propiciado un giro subjetivo, es perfectamente válida la conclusión de que el pasado, del que se nutren no sólo los relatos testimoniales, sino también la Literatura y la Historia, es aprehensible elaborando maquinarias representacionales determinadas inherentemente por las condiciones materiales del sujeto que las enuncia, su locus de enunciación. Sin embargo, y como lo aclara también Sarlo, "Todo testimonio quiere ser creído y, sin embargo, no lleva en sí mismo las pruebas por las cuales puede comprobarse su veracidad, sino que ellas deben venir desde afuera" (47). La problemática de la veracidad no es menor, pues conmina al lector a formularse al menos la inquietud respecto de los procedimientos que emplea el novelista y el historiador, la forma en que manipula sus materias primas:

\footnotetext{
El sujeto no sólo tiene experiencias sino que puede comunicarlas, construir su sentido y, al hacerlo, afirmarse como sujeto. La memoria y los relatos de memoria serían una "cura" de la alienación y la cosificación. Si ya no es posible sostener una Verdad, florecen en cambio unas verdades subjetivas que aseguran saber aquello que, hasta hace tres décadas, se consideraba oculto por la ideología o sumergido en procesos poco accesibles a la introspección simple. No hay Verdad, pero los sujetos, paradójicamente, se han vuelto cognoscibles. (51)
}

Dado que "no hay Verdad", esto es, el pasado no es cognoscible, pero sí lo son los sujetos, el deslinde que realiza Paul Ricoeur en La memoria, la historia, el olvido (2000), respecto de la distinción entre "recordar" y "rememorar", resulta necesario para ingresar al estudio de esta forma de novela histórica. El recuerdo como tal será para Ricoeur un acto espontáneo, humano y que orienta la cotidianeidad. En este sentido, podría afirmarse que es el insumo primario del sujeto ordinario 
mediante el cual éste accede a su pasado mediato e inmediato. Por el contrario, la rememoración implica un proceso de acceso al pasado de mayor sofisticación, un proceso de articulación discursiva compleja, que opera del mismo modo como lo harían los mecanismos representacionales descritos en el apartado anterior. Nos aclara Ricoeur:

La distinción entre mneme [recordar] y anamnesis [rememorar] se basa en dos rasgos: por un lado, el simple recuerdo sobreviene a la manera de una afección, mientras que la rememoración consiste en una búsqueda activa. Por otro lado, el simple recuerdo está bajo la influencia del agente impronta, mientras que los movimientos y toda la secuencia de cambios [...] tienen su principio en nosotros [...]: el acto de acordarse [...] se produce cuando ha pasado el tiempo [...]. Y es este intervalo de tiempo, entre la impresión primera y su retorno, el que recorre la rememoración. En este sentido, el tiempo sigue siendo la apuesta común a la memoria-pasado y a la rememoración-acción. (Ricoeur, 2008: 36; las cursivas son mías)

De lo anterior surge la siguiente pregunta: ¿cómo rememorar el pasado reciente, un pasado que comenzó a gestarse hace más de cuarenta años pero cuyo brazo aún aherroja las condiciones de vida materiales y existenciales del sujeto nacional?

Del problema rememorativo al que alude Ricoeur, de esta "búsqueda activa" en los resquicios del pasado reciente, de esta elaboración de ese pasado, así como también de la subjetividad innata del discurso testimonial y de su credibilidad puesta siempre en entredicho, es de lo que da cuenta una novela histórica como Septiembre sin primavera de Fernando Moure. Esta novela constituye un hito narrativo por al menos cinco razones. Primero, logra articular las voces de tres sujetos en el entramado narrativo (el militante del MAPU, Santiago Mariño; el expatriado español Francisco Mariño, padre de Santiago, también apodado como Paco; una tercera voz narrativa, la de un "escritor aficionado" que organizará el relato testimonial de Paco). Segundo, al relato en primera persona de cada una de las voces se intercala una serie de epístolas, notas personales y textos de prensa que complejizan el artificio tipológico primario de la novela. Tercero, el asunto mismo de la novela abarca un espacio temporal que aborda no sólo los acontecimientos claves de la historia nacional del siglo XX, sino también refiere en sus primeros capítulos los hechos funestos de la Guerra Civil Española que propiciaron el periplo de Francisco Mariño y su arribo final a Chile en el ya legendario Winnipeg. Cuarto, el relato testimonial articulado de Francisco Mariño enfrenta los mismos problemas inherentes a cualquier dispositivo discursivo memorialístico o testimonial (subjetividad, veracidad), a la vez que constituye una búsqueda permanente en el archivo de la memoria propia y ajena, por lo que la narración en sí se concibe como un esfuerzo de doble rememoración: la que realiza el padre del protagonista por traer del pasado y rescatar del olvido las experiencias propias y de su hijo, así como también el esfuerzo escritural que delega a su oyente (la tercera voz narrativa, el "escritor aficionado") para que éste asuma la titánica labor de referir, de acuerdo a las lógicas representacionales que éste conciba pertinentes, la historia referida por Francisco Mariño. Quinto, la novela emplea lo que Grínor Rojo denominaría el procedimiento del "sobredimensionamiento mimético", es decir, las referencias

\footnotetext{
${ }^{7}$ Grínor Rojo ha precisado, a propósito de esta categoría, "que no es infrecuente que estas [las novelas de la dictadura y la postdictadura chilena] sean unas novelas que se exceden a sí mismas, que con el fin de dar cuenta del desmadre que ha ocurrido y sigue ocurriendo en el país sobredimensionan las tintas de su 'realismo' y avanzan de esa manera hasta rasguñar la costra de lo permisible. E incluso arriesgándose con ello de un trastocamiento genérico al apelar a recursos que saltan por sobre los bordes de la literatura tales como la inserción en medio de la materia ficcional de documentos efectiva o pretendidamente dignos de crédito y con los que se prueba la absoluta veracidad de lo que se quiere denunciar" (Rojo, 2016: 59 Volumen 1). Como puede
} 
factuales de la novela exceden sobradamente lo que tradicionalmente se le atribuiría al género en su "condición natural de ficción". Esto trae como consecuencia un artificio narrativo, una forma novelesca que traspone al plano discursivo, su forma, las transformaciones económicas de un espacio social en que cada vez se torna más difusa la distinción realidad-ficción. Es más, la novela se esfuerza por crear esa ambigüedad al situar a su protagonista como sujeto actor y testigo de acontecimientos de la historia nacional por todos conocidos (su militancia en el MAPU, su visita subrepticia al Palacio de La Moneda tras el bombardeo de la mañana del 11 de septiembre, su estadía en Villa Grimaldi, etc.).

Septiembre sin primavera narra, como adelantábamos, las historias imbricadas de Santiago Mariño y su padre, Francisco. El objetivo de este relato es transmitir una experiencia de vida que posiciona como sujeto protagónico a Santiago (según las demandas de su padre), narración que no busca otra cosa que culminar con las certezas e incertezas políticas del mismo, para finalizar con la captura de Santiago y su postrer apremio físico, muerte y desaparición tras su estadía en el centro de tortura y exterminio Villa Grimaldi. Para este fin, Francisco proporciona a la tercera voz algunos insumos:

Guardo algunas carpetas con documentos que hablan de Santiago y otros en los que él habla de sí mismo. Encontrará allí sus notas desordenadas en diversos cuadernos y hojas sueltas, que no configuran un diario de vida propiamente tal, pero recogen parte de sus vivencias y reflexiones. También contiene cierta correspondencia que mantuvimos él y yo, a la que sumé cartas que le fueron enviadas, todo lo cual conservaba en una caja de cartón que su mujer me dejó cuando se fueron. Además, agregué algunas que escribió a miembros de la familia y que me fueron cedidas años más tarde. Por último, Santiago adoptó mi costumbre de coleccionar recortes de prensa que daban cuenta de sucesos significativos para él y que todavía conservo, porque son un testimonio de lo que ocurría alrededor de su vida. (Moure, 2013: 23; las cursivas son mías)

Luego, la tercera voz agregará: "Lo que sigue constituye lo esencial de sus palabras y de la voz de su hijo, que yo he intentado transcribir con la mayor fidelidad, dejando también constancia de los hechos históricos que constituyen su marco" (24). Como se observa en ambos fragmentos, la forma novelesca de Septiembre sin primavera revela la materia prima y disposiciones representacionales de un relato que no distingue entre las experiencias de vida de un sujeto (¿ficcional?, ¿real?), a la vez que las entrelaza a una extensa secuencia de hechos y espacios históricos que tornan superfluo un examen que pretenda diseccionar el relato en términos de qué es imaginado y qué es constatable en los archivos de la Historia. Así, la forma de esta novela histórica traspone al plano discursivo las condiciones económicas de un presente neoliberal que disuelve las diferencias antes mencionadas porque, en este nuevo escenario social, la novela como género requiere de dispositivos que den cuenta de una forma de arte que, más que nunca, evidencie las condiciones materiales y existenciales del individuo del presente. $Y$ para ello necesita perentoriamente desdoblarse de un binarismo que constituye un lastre para tal propósito.

observarse, Grínor Rojo también repara en el carácter deliberado que "fabrica" una ambigüedad capaz de disolver el binarismo ficción-realidad, y que, más allá de cualquier pretensión veritativa, apunta a trastocar los medios de producción escritural: la forma novelesca en el presente neoliberal. 
La gran ciudad. Una novelita finisecular de agitación y propaganda de Omar Saavedra Santis: por una concepción ilustrada del saber literario

Situados en un estadio alternativo, la modalidad "narrativas contraculturales" nos instala en otro nivel de análisis. La novela La gran ciudad, de Omar Saavedra Santis, despliega un relato que comprende un espacio temporal que va desde el triunfo de la Alianza Popular, encabezada por el Compañero Presidente, hasta su posterior debacle propiciada, entre otros personajes y actores, por Bruno Perthel, Benny Ardiles y el diario El Monitor. En relación a su narrador, éste asume tres manifestaciones claras, una de ellas dominante (voz omnisciente), y las otras dos marginales: la primera, un nosotros inclusivo, que analiza varios años después la hecatombe del gobierno derrocado, y que gráficamente se presenta en cursiva; la segunda, los editoriales del diario El Monitor, los que aparecerán también en cursivas como una voz solapada que gradualmente remece la gestión del Gobierno Popular y de las Bibliotecas Populares.

El proyecto central de La gran ciudad se sustenta en una perspectiva sobre el saber y la cultura que nos parece compatible con lo que formulara lmmanuel Kant en “¿Qué es la llustración?” (1784), a propósito de la situación del hombre frente a un poder que lo sojuzga:

La ilustración es la salida del hombre de su minoría de edad. Él mismo es culpable de ella. La minoría de edad estriba en la incapacidad de servirse del propio entendimiento, sin la dirección de otro. Uno mismo es culpable de esta minoría de edad cuando la causa de ella no yace en un defecto del entendimiento, sino en la falta de decisión y ánimo para servirse con independencia de él, sin la conducción de otro. ¡Sapere aude! ¡Ten valor de servirte de tu propio entendimiento! He aquí la divisa de la ilustración. (Kant, 1784: s/p.)

En efecto, al ingresar a la novela corroboramos que los sujetos representados, como Pancho Benavente, Samuel y Marcelo Leyva, así como la enorme masa anónima proletaria, son sujetos que, en un momento determinado de sus vidas, se sitúan en la minoría de edad a la que alude Kant. Caso distinto es el de Oliverio Sotomayor y Federico Neublatt, individuos ilustrados sin duda, "mayores de edad" en la jerga kantiana, quienes experimentan el llamado de la advocación: en el nuevo gobierno de la Alianza Popular serán los responsables, primero Sotomayor y posteriormente Neublatt como su lugarteniente, de propalar la literatura universal en el pueblo sometido a una nescientia secular, de la que se verá liberado sólo por medio del acceso al libro como bien humanitario. En este marco, irrumpirán fuerzas que intentarán por todos los medios frenar estas conquistas, lo que en definitiva desembocará en el derrocamiento del proyecto cultural de la Alianza Popular, la persecución y castigo de los mecenas, pero por sobre todo la instalación de una modalidad de concebir el saber que restituye a los poderes hegemónicos el control de las mentes del pueblo.

El examen de lo anterior, más allá de las evidentes referencias a los mil días de la Unidad Popular de Salvador Allende, la revolución cultural de la Editorial Nacional Quimantú, la desestabilización del gobierno por parte del diario El Mercurio, o el golpe de Estado perpetrado por las Fuerzas Armadas y amparado por los Estados Unidos, revela a lo menos dos problemas de notoria trascendencia, y que permiten comprender cabalmente el desarrollo (o subdesarrollo) cultural de la sociedad chilena del presente. Primero, y como lo han declarado en otro contexto estudiosos como Mario Amorós y Lorena Fuentes, ${ }^{8}$ el plot de la novela

\footnotetext{
${ }^{8}$ A propósito del rol del Estado en la difusión cultural, durante la administración de Allende, las cifras que proporciona Mario Amorós son reveladoras: “A finales de 1973, [Quimantú] había editado 247 títulos con 12.093 .000 ejemplares a precios muy accesibles, 78 de ellos habían sido
} 
anticipa el viraje mercantil que sufrirá la concepción ilustrada de la lectura durante la dictadura y la postdictadura: en un proscenio neoliberal, cuyas dinámicas de mercado y consumo desenfrenado ya no requieren de una noción de libro concebido como dispositivo cognoscitivo, hacen de la obsolescencia el resultado natural de un artefacto que ya no es más un arma emancipatoria, sino simplemente una mercancía orientada a satisfacer placeres inmediatos de entretención, pasatiempo y consumo. Segundo, y probablemente capital para nuestros fines, La gran ciudad articula una estructura narrativa que parodia la díada ficción-realidad por cuanto no escatima en esfuerzos para embozar el referente. Las designaciones antes anotadas (Compañero Presidente, Alianza Popular, El Monitor), o bien otras como el medio litro de leche chocolatada para los niños de la Patria o el Padre Poeta, no son en ningún caso metonímicas, pues no tienen el objetivo de eludir referencias concretas sino conseguir el efecto contrario: hacer explícitas una serie de designaciones que contribuyen, una vez más, a articular un relato histórico que aprehende de manera análoga los procedimientos representacionales de la Literatura y la Historia:

En la tarde siguiente de la Primera Jornada de Lecturas Populares, los bares de la Gran Ciudad fueron escenarios de inflamadas discusiones entre bebedores partidarios del Mío Cid y Don Quijote de la Mancha, entre los que imputaban la calidad del Licenciado Vidriera y los que defendían la impecable oscuridad de Don Luis de Góngora y Argote. Los balcones que colgaban de los cerros se estremecieron con las salvas cruzadas de las madres que encontraban de lo más romántico al Amadís y aquellas que preferían la desfachatez del Diablo Cojuelo. Las pacíficas normas de convivencia que caracterizaban la vida social de la Gran Ciudad se vieron alteradas por un leve hecho de sangre que al cabo de guardia de la $4^{\circ}$ comisaría le costó trabajo ingresarlo al libro de partes. El hecho había nacido de la malhadada idea de la víctima de afirmar que el Lazarillo de Tormes era un niñito maricón si se le comparaba con el Cid que la seguía peleando después de muerto. Lo notable del caso fue que siguió afirmándolo con tres costillas rotas y la nariz hecha morcilla. (Saavedra Santis, 2014: 170)

Valga el fragmento anterior para graficar la disolución del binarismo ficciónrealidad. La Literatura ingresa en la vida de los sujetos históricos y éstos ya no vislumbran las diferencias. Lo que puede colegirse, en consecuencia, es que el artificio narrativo diluye las fronteras entre lo que podría motejarse como imaginario y lo referencial. Así, el procedimiento no metonímico del narrador intenta estatuir un discurso cuyos márgenes representacionales no pueden ser situados con certeza ni en lo ficcional ni en lo factual. Ambas formas de organizar la experiencia se establecerán como mecanismos constituyentes de una misma

reeditados, algunos hasta en su quinta edición, y había 26 títulos agotados pendientes de reimpresión. De todos ellos se habían vendido 11.164 .000 ejemplares, principalmente a través de los kioscos de prensa [...]. Quimantú transformó de manera radical el rol del libro en la sociedad, hasta entonces un bien de lujo, y en aquellos días era frecuente ver a muchos obreros dirigiéndose a su trabajo con un texto de esta editorial en las manos" (Amorós, 2013: 338). Las implicancias culturales que trajo consigo el golpe de Estado son aclaradas por Lorena Fuentes, quien pone en evidencia el giro mercantil que experimentó el país durante el régimen autoritario, y contrastan drásticamente con los números que entrega Amorós: "La particularidad del periodo [...] es que el Estado hace absoluto abandono de su rol de agente cultural y coloca los aparatos de control al servicio de este desplazamiento, potenciando la preeminencia de los criterios mercantiles, la iniciativa privada y la inversión extranjera, e impidiendo todas las prácticas de resistencia que tradicionalmente habían ejercido los movimientos sociales, el sistema político, las organizaciones comunitarias y los propios artistas e intelectuales. Se abre así el camino para que, de manera cada vez más palmaria, la homogenización, la transnacionalización y la concentración de la propiedad se vayan perfilando como los rasgos distintivos de nuestras industrias culturales" (Fuentes, 2015: 175; cursiva del original). 
operación epistemológica: la pesquisa del pasado y los mecanismos representacionales que permiten plasmar dicho tiempo pretérito en el discurso que habla desde el presente.

\section{Precisiones finales}

Las reflexiones que hemos intentado desarrollar tienen un carácter preliminar, pero responden a la necesidad epistemológica de proponer nuevas lecturas para la novela histórica chilena del siglo XXI, bajo los parámetros teóricos de la indistinción entre ficción-realidad que ha sido la ortodoxia en la definición de preceptivas respecto al género. Insistimos en una postura que equipara el estatuto de dos disciplinas para acceder al conocimiento del pasado, pues las dinámicas económicas del presente neoliberal chileno han creado las condiciones para al menos problematizar el rol cultural de la novela histórica en el devenir social, sus mecanismos representacionales, y por supuesto, las formas que articulan para transmitir una experiencia luctuosa como fue el golpe de Estado y las transformaciones económicas que desencadenó, hecho que hoy, a más de cuarenta años, sigue constriñendo el modus vivendi del sujeto nacional. El breve examen de las novelas de Moure y Saavedra Santis intentó precisamente reflejar tales problemáticas.

\section{BiBLIOGRAFÍA}

AMORÓs, Mario (2013), Allende. La biografía. Santiago, Ediciones B.

ARENDT, Hannah (2013), Sobre la revolución. Madrid, Alianza Editorial.

AVELAR, ldelber (2000), Alegorías de la derrota: la ficción postdictatorial y el trabajo del duelo. Santiago, Editorial Cuarto Propio.

BENJAMIN, Walter (2004 [1934]), "El autor como productor", Echeverría, Bolívar (trad.). México, Editorial Ítaca.

FUENTES, Lorena (2015), "El campo cultural chileno y la transición a la democracia: ruptura y continuidades", Mapocho, n. ${ }^{\circ} 77$, pp. 169-190.

GoldMAN, Lucien (1975), Para una sociología de la novela, Ortiz, Gregorio (trad.). Madrid, Editorial Ayuso.

JAMESON, Fredric (1991), El posmodernismo o la lógica cultural del capitalismo tardío. Pérez, Esther y Ferrer y Sonia, Christian (trads). Buenos Aires, Ediciones Imago Mundi.

KANT, Immanuel (1784), “¿Qué es la ilustración?”. Consultado en <http://www.catedras.fsoc.uba.ar/mari/Archivos/HTML/KANT_ilustracion.htm> $(15 / 11 / 2015)$.

LuKÁCS, Georg (1966), "La forma clásica de la novela histórica", La novela histórica. México, Ediciones Era.

(2010), Teoría de la novela. Un ensayo histórico-filosófico sobre las formas de la gran literatura épica. Buenos Aires, Ediciones Godot.

MENTON, Seymour (1993), La Nueva Novela Histórica de la América Latina, 19791992. México, Fondo de Cultura Económica.

MORENO, Fernando (2002), "Apuntes en torno a la tematización de la Historia en la narrativa chilena actual”, Kohut, Karl y Morales Saravia, José (eds.), Literatura chilena hoy. La difícil transición. Madrid, Iberoamericana.

MouRE, Fernando (2013), Septiembre sin primavera. Santiago, Editorial Forja.

Promis, José (2005), "El neopolicial criollo de Ramón Díaz Eterovic", Anales de Literatura Chilena, n. ${ }^{\circ}$ 6, pp. 151-167. 
Ricoeur, Paul (2008), La memoria, la historia, el olvido. Buenos Aires, Fondo de Cultura Económica.

Rojo, Grínor (2016), Las novelas de la dictadura y la postdictadura chilena: ¿Qué y cómo leer? Volumen I. Santiago, LOM Ediciones.

SAAVEDRA SANTIS, Omar (2014), La gran ciudad (Una novelita finisecular de agitación y propaganda). Santiago, Uqbar Editores.

SAlAZAR, Gabriel y PINTO, Julio (2014), Historia contemporánea de Chile III. La economía: mercados, empresarios y trabajadores. Santiago, LOM Ediciones.

SARLO, Beatriz (2007), Tiempo pasado. Cultura de la memoria y giro subjetivo. Una discusión. Buenos Aires, Siglo XXI Editores Argentina.

STEGER, Manfred B. y RoY, Ravi K. (2011), Neoliberalismo. Una breve introducción. Tejada Caller, Paloma (trad.). Madrid, Alianza Editorial.

VIU, Antonia (2007), Imaginar el pasado, decir el presente. La novela histórica chilena (1985-2003). Santiago, RIL Editores. 